\title{
BMJ open Knowledge, attitudes and preferences regarding genetic testing for smoking cessation. A cross-sectional survey among Dutch smokers
}

\author{
Marieke Quaak, ${ }^{1,2}$ Chris Smerecnik, ${ }^{3}$ Frederik J van Schooten, ${ }^{1}$ Hein de Vries, ${ }^{3}$ \\ Constant $P$ van Schayck ${ }^{2}$
}

To cite: Quaak M, Smerecnik $\mathrm{C}$, van Schooten FJ, et al. Knowledge, attitudes and preferences regarding genetic testing for smoking cessation. A cross-sectional survey among Dutch smokers. BMJ Open 2012;2: e000321. doi:10.1136/ bmjopen-2011-000321

- Prepublication history and additional materials for this paper are available online. To view these files please visit the journal online (http:// bmjopen.bmj.com).

Received 18 August 2011 Accepted 7 November 2011

This final article is available for use under the terms of the Creative Commons Attribution Non-Commercial 2.0 Licence; see http://bmjopen.bmj.com

${ }^{1}$ Department of Toxicology, Nutrition and Toxicology Research Institute Maastricht (NUTRIM), Maastricht University, Maastricht, the Netherlands

${ }^{2}$ Department of General Practice, Care and Public Health Research Institute (CAPHRI), Maastricht University, Maastricht, the Netherlands

${ }^{3}$ Department of Health Promotion, Care and Public Health Research Institute (CAPHRI), Maastricht University, Maastricht, the Netherlands

Correspondence to Marieke Quaak; m.quaak@ maastrichtuniversity.nl

\section{ABSTRACT}

Objectives: Recent research strongly suggests that genetic variation influences smokers' ability to stop. Therefore, the use of (pharmaco) genetic testing may increase cessation rates. This study aims to assess the intention of smokers concerning undergoing genetic testing for smoking cessation and their knowledge, attitudes and preferences about this subject.

Design: Online cross-sectional survey.

Setting: Database internet research company of which every inhabitant of the Netherlands of $\geq 12$ years with an email address and capable of understanding Dutch can become a member.

Participants: 587 of 711 Dutch smokers aged $\geq 18$ years, daily smokers for $\geq 5$ years and smoke on average $\geq 10$ cigarettes/day (response rate $=83 \%$ ).

\section{Primary and secondary outcome}

measures: Smokers' knowledge, attitudes and preferences and their intention to undergo genetic testing for smoking cessation.

Results: Knowledge on the influence of genetic factors in smoking addiction and cessation was found to be low. Smokers underestimated their chances of having a genetic predisposition and the influence of this on smoking cessation. Participants perceived few disadvantages, some advantages and showed moderate self-efficacy towards undergoing a genetic test and dealing with the results. Smokers were mildly interested in receiving information and participating in genetic testing, especially when offered by their general practitioner (GP).

Conclusions: For successful implementation of genetic testing for smoking in general practice, several issues should be addressed, such as the knowledge on smoking cessation, genetics and genetic testing (including advantages and disadvantages) and the influence of genetics on smoking addiction and cessation. Furthermore, smokers allocate their GPs a crucial role in the provision of information and the delivery of a genetic test for smoking; however, it is unclear whether GPs will be able and willing to take on this role.

\section{ARTICLE SUMMARY}

Article focus

- Intention of smokers to undergo genetic testing for smoking cessation.

- Smokers' knowledge, attitudes and preferences regarding genetic testing for smoking.

- To aid decisions on the most appropriate strategies for counselling patients and communicating their test results with regard to a genetic test for smoking.

Key messages

- Smokers are mildly interested in receiving more information and participating in genetic testing for smoking cessation, especially when offered by their general practitioner.

- Knowledge on smoking cessation, genetics and genetic testing (including advantages and disadvantages) and the influence of genetics on smoking cessation is low.

Strengths and limitations of this study

- This study provides valuable information on the needs and attitudes of smokers regarding genetic testing for smoking cessation, which can aid decisions for future implementation.

- Under-representation smokers intending to stop smoking might have led to an underestimation of smokers interested in genetic testing.

- Low knowledge level on genetic testing for smoking cessation and genetics in general might have influenced participants' ability to answer the questions.

- Interest in undergoing genetic testing may reflect a generally positive attitude towards genetic testing rather than actual uptake.

- Selection bias might have occurred due to the non-representative nature of the internet population and the self-selection of participants (volunteer effect); however, unlikely due to high response rate $(83 \%)$.

\section{INTRODUCTION}

With currently still over 1.2 billion smokers worldwide, tobacco smoking continues to be 
the largest preventable cause of disease and premature death. ${ }^{1-3}$ Cessation reverses most adverse effects of smoking. ${ }^{4}$ Although most smokers are highly motivated to quit and many (pharmacological) treatments are available to help them, cessation rates remain low; the average 12-month success rate ranges from $15 \%$ to $30 \%,^{5}$ but substantial variability exists in success rates across smokers. Therefore, multiple quit attempts are often required.

Recent research strongly suggests that smokers vary in their underlying genetic susceptibility to become addicted to smoking and their ability to stop smoking. ${ }^{5-9}$ Genetic variation may also influence a smoker's response to a particular smoking cessation pharmacotherapy. Hence, overall effectiveness of smoking cessation pharmacotherapy may potentially be increased if it will be targeted at smokers most likely to respond to a particular type of pharmacotherapy. Reviews concerning preliminary findings of studies investigating the effect of genetic polymorphisms on smoking cessation suggest promising effects, ${ }^{5} 1011$ making the use of (pharmaco) genetic testing for smoking in clinical practice for increasing quit rates by genetically tailored smoking cessation treatment in the near future more likely.

Future implementation of (pharmaco) genetic testing for smoking in daily medical practice, however, will ultimately depend upon smokers' acceptance of these tests. At present, there is relatively little knowledge about the willingness and preferences of smokers concerning genetic testing for smoking addiction and cessation and about individuals' knowledge and attitudes on this subject.

The goal of this study, therefore, is to investigate the intention of smokers to undergo genetic testing for smoking cessation and their knowledge, risk perceptions, attitudes and self-efficacy beliefs. Additionally, we assessed their preferences concerning a genetic test for smoking cessation, such as topics and channels of interest, and test characteristics. This information can be used to guide the future development of a (pharmaco) genetic test for smoking cessation.

\section{METHODS}

\section{Study design}

Smokers' knowledge, attitudes and preferences and their intention to undergo genetic testing were assessed using an online cross-sectional survey.

\section{Recruitment}

Participants were selected from the database of an internet research company originating from Maastricht University (Flycatcher Internet Research B.V., Maastricht, the Netherlands). The company has a database of $\sim 20000$ members from which representative samples can be drawn. Every inhabitant of the Netherlands of $\geq 12$ years with an email address and capable of understanding Dutch can become a member. Members are recruited via digital media, written invitations, face-to-face contacts and intermediaries. Since 2009, the panel is certified with a quality mark (ISO-26326).

Participants were eligible for inclusion if they were aged $\geq 18$ years, were daily smokers for $\geq 5$ years and smoked on average $\geq 10$ cigarettes/day. In total, 711 participants that met the inclusion criteria were approached for this study. Two emails could not be delivered. Of the remaining invitations, 614 people responded. However, 26 questionnaires were not completely filled out, and one case was removed because the fill out time indicated that this participant could not have read the questions before answering. Thus, a total of 587 participants were included in the present study ( response rate $=83 \%$ ).

\section{Questionnaire}

The questionnaire was conducted in Dutch (questions in manuscript translated by authors) and took about $30 \mathrm{~min}$ to complete. Respondents were compensated for their time according to the standard of the research company (eg, respondents receive a number of points which can be exchanged for a gift certificate when a certain amount is reached).

\section{Participant characteristics}

Participants' age, gender and education level were available from the company. In addition, participants were asked questions regarding their smoking behaviour (type of tobacco product, number of cigarettes and/or shags per day, level of nicotine dependence (assessed by the Fagerström Test for Nicotine Dependence ${ }^{12}$ ), previous quit attempts (number, duration, period until last attempt) and intention and intended period to quit.

\section{Knowledge}

Knowledge was assessed using 10 statements (see table 1), two regarding smoking cessation in general, four regarding the influence of genetics on nicotine dependence and four regarding the influence of genetics on smoking cessation (treatment). Participants were asked whether they agreed or disagreed with the statements or did not know the answer. In addition, participants were asked how important environment, personal behaviour and genetic predisposition were according to them as a cause for smoking.

\section{Risk perceptions}

Participants were requested to estimate their probability that they have a genetic predisposition as a result of which they will have more difficulty to stop smoking or they will experience more withdrawal symptoms (1: very small to 5 : very high), as well as to indicate the seriousness of this (1: completely not serious to 5: very serious).

\section{Attitudes and self-efficacy beliefs}

Attitudes towards undergoing genetic testing were assessed by 10 questions on the perceived advantages and 10 questions on the disadvantages and self-efficacy 
Table 1 Knowledge of smoking cessation and influence of genetic factors on smoking addiction and smoking cessation (treatment)

Correct (\%) Incorrect (\%) Don't know (\%)

Smoking cessation

It is important to quit smoking, even if you already smoke for a very long time ( $\mathrm{T}$ )

More than half of the smokers who want to quit smoking succeed

in quitting $(F)$

Influence of genetic factors on smoking addiction levels

The chance to become addicted to smoking is influenced by the

presence of certain hereditary traits (genes) ( $T$ )

Genes exist that increase the chance to become addicted to

smoking ( $\mathrm{T}$ )

Genes exist that decrease the chance to become addicted to

smoking $(T)$

A parent with a genetic predisposition to get addicted to smoking

will transfer this predisposition to its children, even when the parent

doesn't smoke or has never smoked $(T)$

Influence of genetic factors on smoking cessation (treatment)

A genetic predisposition to get addicted to smoking might also influence

ones chance to quit smoking $(\mathrm{T})$

Due to a genetic predisposition can a smoking cessation therapy

(eg, nicotine patches) be less effective for certain smokers $(T)$

Due to a genetic predisposition can a smoking cessation therapy

(eg, nicotine patches) be more effective for certain smokers ( $T$ )

A genetic predisposition can influence the chance on withdrawal symptoms during a cessation attempt $(T)$

$\mathrm{T}$, this statement is true; $\mathrm{F}$, this statement is false.

(eg, ability to undergo a genetic test and to deal with the results) using four questions (1: completely disagree to 5: completely agree; see table 2).

\section{Topics and channels of interest}

Participants were asked about which of the given topics they would like to receive more information, via which channels they would prefer to receive more information regarding a genetic test to help them stop smoking and via which channels they would prefer to actually obtain the test.

\section{Test characteristics}

Participants were asked how important a number of test characteristics (easily performable, reliability, fast result, sharp increased cessation rates, low price, covered by insurance) were for them when they would consider to undergo a genetic test to help them stop smoking (1: very unimportant to 5 : very important). Furthermore, participants were asked which maximum price they would be willing to pay for the genetic test.

\section{Intention to undergo genetic testing}

Participants were asked if they were planning to undergo a genetic test to determine which smoking cessation therapy they could use best and if they were planning to undergo a genetic test if it was offered by their general practitioner (GP) or if they would ask their GP for a genetic test (1: strongly disagree to 5: strongly agree).

\section{RESULTS}

\section{Participant characteristics}

Participant characteristics and characteristics of the general Dutch smoking population can be found in table 3. No significant differences were found in terms of gender, age group, education level, amount of cigarette smokers and number of cigarettes smoked. Slightly more participants had attempted to quit smoking and they had undertaken slightly more quit attempts. A larger part of the sample smoked shag (rolling tobacco), but fewer smoked pipe/cigar/cigarillo's. Furthermore, participants seemed less interested in quitting than the general smoking population.

\section{Knowledge}

Table 1 presents the percentage of correct, incorrect and 'don't know' answers.

The first set of statements concerned respondents' knowledge about smoking cessation. Overall, 88.9\% knew that it is important to quit. About half $(49.1 \%)$ of the respondents knew that less than half of the smokers who want to quit succeed, while $29.8 \%$ could not answer this question.

The second set measured whether respondents were aware of how genetic factors influence smoking addiction levels. About half of the participants could not answer these questions $(42.6 \%-59.6 \%)$. The lowest percentage of correct scores was found for the statements regarding the transfer of a genetic predisposition 
Table 2 Attitudes and self-efficacy beliefs

\begin{tabular}{|c|c|c|c|c|c|}
\hline & $\begin{array}{l}\text { Completely } \\
\text { disagree (\%) }\end{array}$ & $\begin{array}{l}\text { Disagree } \\
(\%)\end{array}$ & $\begin{array}{l}\text { Neutral } \\
(\%)\end{array}$ & $\begin{array}{l}\text { Agree } \\
(\%)\end{array}$ & $\begin{array}{l}\text { Completely } \\
\text { agree (\%) }\end{array}$ \\
\hline \multicolumn{6}{|l|}{ Disadvantages } \\
\hline \multicolumn{6}{|l|}{ If I would undergo a genetic test... } \\
\hline $\begin{array}{l}\text {...the results will become known at my work/to } \\
\text { my employer. }\end{array}$ & 39.9 & 29.3 & 26.1 & 3.9 & 0.9 \\
\hline $\begin{array}{l}\text {...the results will become known to my health } \\
\text { insurance. }\end{array}$ & 23.7 & 20.6 & 33.2 & 18.9 & 3.6 \\
\hline $\begin{array}{l}\text {...and it will show that I am addicted to smoking } \\
\text { will it be more difficult to get a mortgage or } \\
\text { life-insurance. }\end{array}$ & 19.4 & 22.1 & 32.7 & 19.9 & 5.8 \\
\hline $\begin{array}{l}\text {...the results may be passed on to all kinds } \\
\text { of agencies. }\end{array}$ & 21.8 & 26.6 & 34.6 & 12.9 & 4.1 \\
\hline $\begin{array}{l}\text {...I will learn about other diseases I have a } \\
\text { predisposition for. }\end{array}$ & 11.8 & 15.5 & 43.3 & 26.1 & 3.4 \\
\hline ...I will be worried for the results. & 9.0 & 24.7 & 40.4 & 23.2 & 2.7 \\
\hline ...I will be afraid of the results. & 10.9 & 27.4 & 42.2 & 16.5 & 2.9 \\
\hline ...I will regret it due to possible consequences. & 10.4 & 27.9 & 44.5 & 14.8 & 2.4 \\
\hline $\begin{array}{l}\text {..I will worry about the possible results of the } \\
\text { genetic test. }\end{array}$ & 9.7 & 22.7 & 40.0 & 23.9 & 3.7 \\
\hline ...I will not be able to tell the results to others. & 15.0 & 38.2 & 38.8 & 6.6 & 1.4 \\
\hline \multicolumn{6}{|l|}{ Advantages } \\
\hline $\begin{array}{l}\text {...this will indicate the correct smoking cessation } \\
\text { therapy for me. }\end{array}$ & 4.6 & 13.5 & 55.5 & 21.5 & 4.9 \\
\hline $\begin{array}{l}\text {...this will increase the chances that I succeed } \\
\text { to stop smoking. }\end{array}$ & 6.1 & 13.8 & 54.9 & 20.6 & 4.6 \\
\hline $\begin{array}{l}\text {...this will help to determine the correct dose of } \\
\text { smoking cessation medication. }\end{array}$ & 5.1 & 10.6 & 51.4 & 27.8 & 5.1 \\
\hline $\begin{array}{l}\text {...I will have less side-effects from smoking } \\
\text { cessation treatments. }\end{array}$ & 6.0 & 16.5 & 61.0 & 13.5 & 3.1 \\
\hline $\begin{array}{l}\text {...this can prevent that I take/undergo an incorrect } \\
\text { smoking cessation treatment. }\end{array}$ & 5.5 & 11.1 & 56.4 & 22.0 & 5.1 \\
\hline \multicolumn{6}{|l|}{$\begin{array}{l}\text { everything I can to understand my smoking } \\
\text { addiction. }\end{array}$} \\
\hline ...I will feel relieved by the results. & 7.8 & 15.8 & 43.1 & 29.5 & 3.7 \\
\hline ...I will be proud of myself. & 9.0 & 21.3 & 52.5 & 14.8 & 2.4 \\
\hline ...I will be happy that I know my genetic risk. & 9.5 & 19.9 & 45.5 & 21.3 & 3.7 \\
\hline ...l will feel reassured. & 12.6 & 21.6 & 50.3 & 14.1 & 1.4 \\
\hline \multicolumn{6}{|l|}{ Self-efficacy } \\
\hline \multicolumn{6}{|l|}{ Do you believe you will be able to... } \\
\hline ...undergo a genetic test? & 7.5 & 18.2 & 38.0 & 20.3 & 16.0 \\
\hline $\begin{array}{l}\text {...ask you GP for a genetic test when you have a } \\
\text { need for it? }\end{array}$ & 7.2 & 20.4 & 39.7 & 20.1 & 12.6 \\
\hline ...understand the results of the genetic test? & 3.2 & 8.0 & 48.9 & 27.3 & 12.6 \\
\hline $\begin{array}{l}\text {...undergo the correct treatment based on the } \\
\text { results of the genetic test? }\end{array}$ & 4.6 & 10.6 & 49.2 & 17.5 & 18.1 \\
\hline
\end{tabular}

to the offspring by a non-smoking parent and the existence of genes that decrease the chance of becoming addicted to smoking ( $14.0 \%$ and $15.5 \%$, respectively). About one-third knew that the chance to become addicted to smoking is influenced by genes $(29.5 \%)$ and that genes exist that increase the chance of becoming addicted to smoking $(33.4 \%)$.

The third set assessed knowledge of the influence of genetic factors on smoking cessation and smoking cessation treatment. More than half of the respondents could not answer these $(53.5 \%-60.3 \%)$. About a quarter knew that a genetic predisposition might also influence ones chances to quit $(25.4 \%)$, can make cessation therapy less effective for certain smokers (26.4\%) and influences the chance on withdrawal symptoms during cessation (23.9\%). Only $15.2 \%$ knew that a genetic predisposition can also make a cessation therapy more effective for certain smokers. 
Table 3 Baseline characteristics of the research sample (compared with the general smoking population)

\begin{tabular}{|c|c|c|c|c|}
\hline & \multicolumn{3}{|c|}{ Sample $(n=587)$} & \multirow{2}{*}{$\begin{array}{l}\text { Dutch smoking } \\
\text { population* }\end{array}$} \\
\hline & n/mean & $\% / S D$ & Range & \\
\hline \multicolumn{5}{|l|}{ Demographics } \\
\hline \multicolumn{5}{|l|}{ Gender (n, \%) } \\
\hline Male & 292 & 49.7 & & $53.6 \%$ \\
\hline Female & 295 & 50.3 & & $46.4 \%$ \\
\hline \multicolumn{5}{|l|}{ Age $(n, \%)$} \\
\hline 20-39 years & 192 & 32.7 & & $41.0 \%$ \\
\hline $40-64$ years & 336 & 57.2 & & $50.7 \%$ \\
\hline$>65$ years & 59 & 10.1 & & $8.3 \%$ \\
\hline \multicolumn{5}{|l|}{ Level of education (n, \%) } \\
\hline Low & 184 & 31.3 & & $39.0 \%$ \\
\hline Medium & 267 & 45.5 & & $36.6 \%$ \\
\hline High & 136 & 23.2 & & $24.4 \%$ \\
\hline \multicolumn{5}{|l|}{ Smoking characteristics } \\
\hline \multicolumn{5}{|l|}{ Type of tobacco product smoked (n, \%) } \\
\hline Cigarettes & 430 & 73.3 & & $67.0 \%$ \\
\hline Shag (rolling tobacco) & 360 & 61.3 & & $48.0 \%$ \\
\hline Pipe/cigars/cigarillo's & 28 & 4.8 & & $17.0 \%$ \\
\hline Other & 5 & 0.8 & & - \\
\hline $\begin{array}{l}\text { Number of cigarettes/shags smoked per day } \\
\text { (mean, SD) }\end{array}$ & 19.0 & 7.5 & $10-50$ & 14.4 \\
\hline FTND score (mean, SD) & 4.6 & 2.1 & $0-10$ & - \\
\hline FTND score $>6(n, \%)$ & 215 & 36.6 & & - \\
\hline \multicolumn{5}{|l|}{ Cessation characteristics } \\
\hline Previously attempted to quit (n, \%) & 437 & 74.4 & & $65.0 \%$ \\
\hline Number of previous attempts to quit (mean, SD) & 2.9 & 3.1 & $1-40$ & 2.2 \\
\hline Duration longest quit attempt, days (mean, SD) & 269.7 & 623.1 & $0-4015$ & - \\
\hline Period until last quit attempt, years (mean, SD) & 3.9 & 5.1 & $0-30$ & - \\
\hline Intention to quit smoking $(\mathrm{n}, \%)$ & 305 & 52.0 & & $78.0 \%$ \\
\hline \multicolumn{5}{|l|}{ Intended period until quit attempt, years $(n, \%)$} \\
\hline Within 1 month & 22 & 3.7 & & $11.0 \%$ \\
\hline Within 3 months & 53 & 9.0 & & $13.0 \%$ \\
\hline Within 6 months & 50 & 8.5 & & \\
\hline Within 1 year & 109 & 18.6 & & $14.0 \%$ \\
\hline More than 1 year from now & 71 & 12.1 & & $40.0 \%$ \\
\hline
\end{tabular}

Furthermore, most respondents believed that environment and personal behaviour were (very) important causes for smoking ( $80 \%$ and $84 \%$, respectively), while only $36 \%$ believed that genetic predisposition is an (very) important cause of smoking (supplementary figure S1).

\section{Risk perceptions}

About one-third of the participants believed their probability to be (very) small to have a genetic predisposition as a result of which they will have more difficulty to stop smoking $(38.3 \%)$ or have more withdrawal symptoms (39.4\%) (supplementary table S1). On the other hand, about one-fifth (16.8\% and $15.3 \%$, respectively) believed their probability to be (very) big.

About half of the participants believed this to be (very) serious $(53.9 \%$ and $51.5 \%)$, about two-fifth $(35.6 \%$ and $39.2 \%)$ to be neutral and about one-tenth $(9.4 \%$ and $10.6 \%$ ) to be (completely) not serious (supplementary table S1).

\section{Attitudes and self-efficacy beliefs}

Attitudes regarding genetic testing (perceived advantages and disadvantages) and self-efficacy beliefs can be found in table 2.

About one-third to half of the participants did not agree with the statements about the disadvantages of genetic testing and about one-third to two-fifth had a neutral reaction, while only less then one-third (completely) agreed with these statements. Especially, the chance that the results would become known at work or to the employer and that they would not be able to tell others was perceived as low $(4.8 \%$ and $8.0 \%$ (completely) agreed, respectively).

On the other hand, only about one-third or less (completely) disagreed with the statements on the advantages of genetic testing $(12.8 \%-34.2 \%)$, while about half $(43.1 \%-61.0 \%)$ had a neutral reaction and $12.8 \%-33.2 \%$ (completely) agreed. Participants were least convinced that they would be relieved by the results and most convinced that a genetic test would give 
a reliable result about the presence of a genetic predisposition to become addicted to smoking, and that it could help to determine the correct dose of smoking cessation medication.

About a quarter of the participants were unsure if they would be able to ask their GP for a genetic test or undergo a genetic test $(27.6 \%$ and $25.7 \%$, respectively), while about two-fifth $(39.7 \%$ and $38.0 \%)$ had a neutral reaction and one-third (32.7\% and $36.3 \%$ ) (totally) agreed with these statements. Furthermore, they agreed even somewhat more to the beliefs that they would be able to undergo the correct treatment based on the results of the test and to understand the results of the genetic test. Only, about 10\%-15\% (totally) disagreed with these statements, about half $(48.9 \%$ and $49.2 \%$, respectively) did not agree or disagree with them and about two-fifth (39.9\% and 35.6\%) (totally) agreed with them.

\section{Topics and channels of interest}

About one-third of the participants (29.3\%) were not interested in more information (see supplementary figure S2A). However, 28.4\% were interested in more information on how DNA works, $35.8 \%$ in what a genetic predisposition is and $50.9 \%$ in the working mechanism of a genetic test. Furthermore, $42.9 \%$ were interested in where more information can be found about the genetic background of smoking and $43.1 \%$ in more information about the influence of genetic differences on (smoking cessation) treatments.

Most participants $(73.6 \%)$ would prefer to receive more information from their GP (supplementary figure S2B). Other channels via which participants would prefer to receive more information are the internet $(48.0 \%)$, specialists $(37.6 \%)$, leaflets $(22.5 \%)$, TV $(12.4 \%)$, newspapers $(7.7 \%)$, friends $(6.0 \%)$, a telephonic help-desk $(5.3 \%)$, magazines $(4.9 \%)$, radio $(2.4 \%)$ and books $(2.2 \%)$.

Most participants $(67.6 \%)$ would also prefer to obtain the genetic test via their GP (supplementary figure S2C). Other preferred channels for obtaining the test were expert/specialist (33.4\%), the pharmacy (18.1\%), internet $(15.5 \%)$ and the pharmacist $(9.2 \%)$, while $15.5 \%$ was not interested in obtaining a genetic test.

\section{Test characteristics}

The most important test characteristic according to the participants of this study is reliability (supplementary figure S3); $82 \%$ of the participants believed this to be (very) important. Other test characteristics were also indicated as (very) important by most participants; covered by insurance $(78 \%)$, a low price $(74 \%)$, a sharp increase in cessation rates $(71 \%)$ and a fast result $(65 \%)$.

Most participants $(64.7 \%)$ indicated not to be willing to pay $>€ 50$ for the genetic test. About a quarter of the participants $(24.2 \%)$ are willing to pay $€ 50-€ 150$, $8.9 \%$ willing to pay $€ 150-€ 200$ and only $2.2 \%$ is willing to pay $>€ 200$.
Intention to undergo genetic testing

Only a low number of participants (16.6\%) were (completely) interested in undergoing a genetic test to determine which smoking cessation therapy they could use best (see supplementary table S2). From the remaining participants, slightly less than half were (completely) not interested in undergoing a genetic test $(43.5 \%)$ and about the same proportion was undecided as to whether or not they would be willing to undergo a genetic test $(40.0 \%)$.

The intention to undergo genetic testing increased considerably when it would be offered by their GP $(38.3 \%)$. On the other hand, only $7.8 \%$ would ask their GP for the genetic test, while about half of the participants (50.6\%) would not ask their GP for the test.

\section{DISCUSSION}

Significant advances have been made in elucidating the role of genetic factors in nicotine dependence and response to smoking cessation treatment. Although much work still remains to be done, the use of genetic testing for increasing quit rates by genetically tailored smoking cessation treatment in clinical practice is on the horizon. However, at present, few studies have investigated the needs and attitudes of smokers on this subject. Therefore, in this study, we investigated knowledge, attitudes and preferences of smokers on genetics of smoking and their willingness to undergo genetic testing for smoking addiction and treatment.

This study provides valuable information, which can aid decisions on the most appropriate strategies for counselling patients and communicating their test results.

The results showed that misconceptions regarding smoking cessation rates using current smoking cessation (pharmaco) therapies need attention. Even though most smokers knew it is important to quit smoking, only about half of them knew that less than half of the smokers who want to quit smoking will succeed. In practice cessation, rates are even much lower; only $15 \%-30 \%$ will succeed in long-term quitting using the available treatments, ${ }^{5}$ and these rates are even lower when no treatment is used. Since smokers overestimate their chances to be able to quit smoking using the current (pharmaco) therapies, they might underestimate the positive effects of a genetic test for smoking. However, we should be careful with presenting this information to smokers since this might also demotivate smokers to start a quit attempt.

The knowledge level on the influence of genetic factors on smoking addiction and cessation, and possibly also basic mechanisms of heredity, is highly inadequate and should be addressed as well. These results are comparable with a previous study, ${ }^{13}$ which also found that smokers, ex-smokers and non-smokers had little knowledge about genetic contributions to smoking and smoking-related behaviours. Furthermore, the most popular topics for receiving more information were the 
working mechanism of a genetic test, where more information about the genetic background of smoking can be found, and the influence of genetic differences on (smoking cessation) treatments. This confirms the lack of knowledge about the influence of genetics on smoking and smoking cessation that was found in this study. Moreover, about one-third of the participants were also interested in more information on what a genetic predisposition is and how DNA works, indicating a further lack of knowledge on genetics in general.

Besides, smokers seem to considerably underestimate their chances of having a genetic predisposition and the influence of this on smoking and smoking cessation, which could lead to an underestimation of the importance of undergoing a genetic test for smoking as well. Respondents were found to perceive the probability of having a genetic predisposition to be (very) small to average, even though many of the genetic variants that have been shown to influence smoking behaviour are prevalent in the population. ${ }^{6}{ }^{14}$ Comparable results were found by another study, ${ }^{13}$ in which $53 \%$ perceived themselves as "not at all likely" or "somewhat likely" to have inherited a genetic predisposition to smoking, while $47 \%$ perceived themselves to be 'moderately' to 'extremely likely'. Furthermore, we found that most participants did not belief that a genetic predisposition is an (very) important cause of smoking, while it has been shown that genetic factors account for a vast part of the variance in smoking initiation, maintenance and cessation success. ${ }^{5}$ 7-9 In the previously mentioned study, also only a small part of the participants believed that inheriting a gene that predisposes them to smoke is the most important factor that causes people to smoke, although smokers were significantly more likely to agree with this. ${ }^{13}$ Recently, we have shown in a theoretical modelling study based on the results of this survey that smokers who perceive a higher susceptibility or severity have a higher intention to undergo genetic testing. ${ }^{15}$ Thus, increasing awareness of the probability and consequences of having a genetic predisposition might also be an effective strategy to motivate smokers to undergo a genetic test for smoking cessation.

Moreover, participants were found to perceive little disadvantages of genetic testing for smoking addiction and cessation but some advantages. Only a small part of the participants in this study were concerned that the results would become known at their work or to their employer, their health insurance or other agencies and that it would become more difficult to get a mortgage or life insurance when a genetic test would show that they were addicted to smoking. On the contrary, research in other areas has shown that those in the USA are particularly concerned about the potential for genetic test results to become available to their employer, health insurance or life insurance. ${ }^{16} 17$ These differences might be explained by the difference in laws in place to protect against the misuse of genetic information by employers and insurers. In some countries, genetic testing is explicitly regulated with regard to all aspects (eg, Austria, the Netherlands and Norway); in others; the regulation has focused only on the insurance industry (eg, Denmark and Sweden) or even only on group health insurers (eg, USA). ${ }^{18}$ Therefore, to motivate smokers to undergo a genetic test, they could be made more aware of the advantages of genetic testing as well. However, disadvantages should not be under-represented either because smokers may then inaccurately perceive the benefits and risks associated with genetic testing. Since fear has been shown to decrease intention to undergo genetic testing in our theoretical modelling study, ${ }^{15}$ increasing awareness of advantages and disadvantages could decrease fear for genetic testing and might thereby result in an increased uptake of a genetic test for smoking cessation.

Uptake might be further increased when smoker's ability to undergo a genetic test and deal with the results (eg, self-efficacy) is improved. Currently, only 30\%-40\% of the participants believed to be able to cope with a genetic test for smoking cessation. In our theoretical modelling study, intention to undergo genetic testing was found to increase when smokers feel they would be able to cope with the results. ${ }^{15}$

Finally, it seems that smokers allocate their GPs a crucial role in the provision of information on this subject and the delivery of a genetic test for smoking. Thus, it seems likely that GPs will play an important role in the counselling of patients about undergoing genetic testing. However, several studies indicate that they may not have the knowledge, willingness or training to take on this role. ${ }^{19-22}$ Many GPs were not sure if they would be able to understand the meaning of genetic test results, how such information should direct clinical care and their ability to effectively communicate genetic information to patients. ${ }^{21}$ Furthermore, physicians are concerned that integrating genetic testing into their practice would also add to their already restricted time constraints. ${ }^{21}$

Thus, for successful implementation of genetic testing for smoking in general practice, several issues should be addressed, such as the knowledge on smoking cessation, genetics and genetic testing (including advantages and disadvantages) and the influence of genetics on smoking addiction and cessation. Of course, patients are not expected to be experts in this field. However, patients will need to have a certain level of insight on this subject. Without this knowledge, smokers will not be able to understand the test and the results properly. Therefore, they will not be able to make an accurate decision whether or not to undergo a genetic test for smoking nor to undergo the right treatment based on the results. GPs are likely to play an important role in the information provision since they will have to help their patients to make the decision to undergo a genetic test and provide them with the treatment based on this test. However, due to the time constraints, it will probably not possible for a GP to fully explain this test to their patients 
during a consult. And furthermore, patients might not be interested in such a test if they do not have some knowledge about the influence of genetic factors on smoking and smoking cessation. Therefore, these issues should also be addressed via other channels of communication, for instance, information leaflets or information campaigns on $\mathrm{TV}$, radio or in magazines or newspapers.

This study is subject to several limitations. First, the field of pharmacogenetic influences on smoking cessation is still in its infancy, and therefore, no well-accepted tests to tailor smoking cessation treatment are commonly available. However, it is of crucial importance to investigate the expectations of the smokers that are willing to quit before a genetic test can be developed that will enter the market. This knowledge on smokers' expectations can drive the implementation, promotional strategy and the information given when the test will become available. Therefore, from a health promotion and marketing perspective, it is appropriate to start asking these questions at this time.

Second, as smokers may not be familiar with genetic testing for smoking addiction and genetically tailored cessation treatments or even genetics in general, it is questionable whether they were able to give a well-considered answer to all our questions.

Third, as Sanderson and colleagues ${ }^{23}$ argued, interest in undergoing genetic testing may reflect a generally positive attitude towards genetic testing rather than actual uptake. Thus, to determine actual uptake of genetic testing, further studies are needed where respondents are offered the possibility to undergo genetic testing.

Fourth, our sample under-represented smokers intending to stop smoking, which could have led to an underestimation of the willingness to undergo genetic testing.

Fifth, since participants were recruited via an internet research company, selection bias might have occurred due to the non-representative nature of the internet population and the self-selection of participants (volunteer effect). The effect of bias due to the non-representative nature of the internet population will probably be minimal since no difference in internet use is expected among smokers. The potential for self-selection bias can be estimated by measuring the response rate; the fairly high response rate $(83 \%)$ decreases the chance for selection bias. Furthermore, several studies have shown that the validity and reliability of data obtained online are comparable to those obtained by classical methods. ${ }^{24-28}$

Finally, since this survey was conducted among Dutch smokers only, the results might not be completely generalisable to other smoking populations. Genetic testing is explicitly regulated in the Netherlands ${ }^{18}$; therefore, it is to be expected that smokers perceive less disadvantages of genetic testing than smokers in other countries were regulation is less explicit. Smokers are thus likely to perceive more disadvantages of genetic testing in countries with less regulation, as has been found in the USA, ${ }^{16}{ }^{17}$ which might decrease their intention to undergo genetic testing for smoking cessation. Furthermore, the level of education is likely to influence the knowledge level. However, since the education level in the Netherlands is relatively high and even here the knowledge level is low, it is not to be expected that the knowledge level is adequate in other countries. Indeed, comparable results have been found before. ${ }^{13}$ Moreover, in the Netherlands, the GP plays a central role in the provision of healthcare and that is probably why Dutch smokers allocate their GPs an important role in the provision of information and the genetic test itself. This could be different for countries with another healthcare system. However, it is to be expected that intention will be increased when it is offered by the primary healthcare provider in other countries as well, regardless of the type of primary healthcare provider. However, the general conclusions will probably also apply to other countries. And the results from this study also provide a good starting point for the investigation of this issue among other populations.

In general, we may conclude that Dutch smokers are interested in genetic testing for smoking cessation, especially when offered by their GP. However, before successful implementation of genetic testing for smoking in general practice will be possible, several issues should be addressed, such as the knowledge on smoking cessation, genetics and genetic testing (including advantages and disadvantages) and the influence of genetics on smoking addiction and cessation. Furthermore, GPs attitudes and knowledge should be addressed as well.

Funding This work was supported by a grant from the Netherlands Organization for Health Research and Development (ZonMW, The Hague; Project No. 50-50101-96-404).

Competing interests CPvS reported having received financing (grant, consultancy and/or travel/accommodation costs) from AstraZeneca, Boehringer Ingelheim and Pfizer, unrelated to this study. MQ, CS, HdV and FJvS declare no conflicts of interest.

Contributors $M Q$ and $C S$ designed the survey and wrote the analysis plan. MQ analysed the data and drafted the manuscript. C revised the draft paper. FJvS HdV and CPvS supervised the designing of the survey and revised the draft paper.

Provenance and peer review Not commissioned; externally peer reviewed.

Data sharing statement No additional data available.

\section{REFERENCES}

1. Guindon GE, Boisclair D. Past, Current and Future Trends in Tobacco Use. HNP Discussion Paper no.6. Economics of Tobacco Control Paper No. 6. UC San Francisco: WHO Tobacco Control Papers, Center for Tobacco Control Research and Education, 2003.

2. World Health Organization. The World Health Report 2003-Shaping the Future. Geneva: World Health Organization, 2003.

3. Mucha L, Stephenson J, Morandi N, et al. Meta-analysis of disease risk associated with smoking, by gender and intensity of smoking. Gend Med 2006;3:279-91.

4. Taylor DH Jr, Hasselblad V, Henley SJ, et al. Benefits of smoking cessation for longevity. Am J Public Health 2002;92:990-6. 
5. Quaak M, van Schayck CP, Knaapen AM, et al. Genetic variation as a predictor of smoking cessation success. A promising preventive and intervention tool for chronic respiratory diseases? Eur Respir $J$ 2009;33:468-80.

6. Batra V, Patkar AA, Berrettini WH, et al. The genetic determinants of smoking. Chest 2003;123:1730-9.

7. Li MD, Cheng R, Ma JZ, et al. A meta-analysis of estimated genetic and environmental effects on smoking behavior in male and female adult twins. Addiction 2003:98:23-31.

8. Munafò MR, Johnstone EC. Genes and cigarette smoking. Addiction 2008;103:893-904.

9. Kaprio J. Genetic epidemiology of smoking behavior and nicotine dependence. COPD 2009;6:304-6.

10. Kortmann GL, Dobler CJ, Bizarro L, et al. Pharmacogenetics of smoking cessation therapy. Am J Med Genet B Neuropsychiatr Genet 2010;153B:17-28.

11. Quaak M, van Schayck CP, Knaapen AM, et al. Implications of genedrug interactions in smoking cessation for improving the prevention of chronic degenerative diseases. Mutat Res 2009;667:44-57.

12. Heatherton TF, Kozlowski LT, Frecker RC, et al. The Fagerström Test for Nicotine Dependence: a revision of the Fagerström Tolerance Questionnaire. Br J Addict 1991;86:1119-27.

13. Houfek JF, Atwood JR, Wolfe RM, et al. Knowledge and beliefs about genetics and smoking among visitors and staff at a health care facility. Public Health Nurs 2008;25:77-87.

14. Lerman C, Caporaso NE, Audrain J, et al. Evidence suggesting the role of specific genetic factors in cigarette smoking. Health Psychol 1999;18:14-20.

15. Smerecnik C, Quaak M, van Schayck CP, et al. Are smokers interested in genetic testing for smoking addiction? A socio-cognitive approach. Psychol Health 2011;26:1099-112.

16. Lapham EV, Kozma C, Weiss JO. Genetic discrimination: perspectives of consumers. Science 1996;274:621-4.

17. Hall MA, McEwen JE, Barton JC, et al. Concerns in a primary care population about genetic discrimination by insurers. Genet Med 2005;7:311-16.
18. Murthy A, Dixon A, Mossialos E. Genetic testing and insurance. $J$ R Soc Med 2001;94:57-60.

19. Baars MJ, Henneman L, Ten Kate LP. Deficiency of knowledge of genetics and genetic tests among general practitioners, gynecologists, and pediatricians: a global problem. Genet Med 2005; $7: 605-10$

20. Shields $A E$, Blumenthal $D$, Weiss $K B$, et al. Barriers to translating emerging genetic research on smoking into clinical practice. Perspectives of primary care physicians. $J$ Gen Intern Med 2005;20:131-8.

21. Park ER, Kleimann S, Pelan JA, et al. Anticipating clinical integration of genetically tailored tobacco dependence treatment: perspectives of primary care physicians. Nicotine Tob Res 2007;9:271-9.

22. Suther S, Goodson P. Barriers to the provision of genetic services by primary care physicians: a systematic review of the literature. Genet Med 2003;5:70-6.

23. Sanderson SC, O'Neill SC, Bastian LA, et al. What can interest tell us about uptake of genetic testing? Intention and behavior amongst smokers related to patients with lung cancer. Public Health Genomics 2010;13:116-24.

24. Krantz JH, Ballard J, Scher J. Comparing the results of laboratory and World-Wide Web samples on the determinants of female attractiveness. Behav Res Methods Instrum Comput 1997;29:264-9.

25. Buchanan T, Smith JL. Using the Internet for psychological research personality testing on the World Wide Web. Br J Psychol 1999;90:125-44.

26. Buchanan T, Smith JL. Research on the Internet: validation of a World-Wide Web mediated personality scale. Behav Res Methods Instrum Comput 1999;31:565-71.

27. Nathanson AT, Reinert SE. Windsurfing injuries: results of a paperand Internet-based survey. Wilderness Environ Med 1999;10:218-25.

28. Senior C, Phillips ML, Barnes J, et al. An investigation into the perception of dominance from schematic faces: a study using the World-Wide Web. Behav Res Methods Instrum Comput 1999;31:341-6. 